\title{
A prospective study on the pharmacotherapy of bronchial asthma in pediatric patients at a tertiary care hospital; emphasis on adverse drug reactions
}

\author{
Bansal S. ${ }^{1}$, Une L. ${ }^{*}$ \\ DOI: https://doi.org/10.17511/ijpr.2020.i02.10 \\ 1 Sharad Bansal, Associate Professor, Department of Paediatrics, JIIU's Indian Institute of Medical Science and Research, Jalna, \\ Maharashtra, India. \\ 2* Lalit Une, Professor and Head, Department of Paediatrics, JIIU's Indian Institute of Medical Science and Research, Jalna, Maharashtra, \\ India.
}

Background: Paediatric asthma is one of the most common chronic illnesses in childhood and affects the quality of life in children. Anti-asthmatic drugs used in children may result in a beneficial and adverse drug reaction ( $A D R$ ) and could contribute significantly to morbidity and mortality. Several studies report about the safety and efficacy of asthma medications in adults but the information in children is limited. Material and Methods: A prospective, observational, noninterventional study of children who presented between January 2018 and December 2019 to the Department of Paediatric of Noor Hospital. Pediatric patients of bronchial asthma (both acute and chronic cases) of either gender within the age limit of 1-13 years who attended the outpatient department (OPD) as well as the inpatient department (IPD) were included in the study. Results: Out of 120 patients, most of the pediatric patients suffering from asthma $42 \%$ were found in the age group of 5-8 years followed by (39\%) 1-4 years and the last one is $9-13$ years (19\%). Demographic analysis of data revealed that there were $61.6 \%$ male and $38.4 \%$ female in the study. Out of 120 Paediatric asthma patients, 34.1\% were suffering from mild persistent and the remaining $59.1 \%$ were patients of moderate persistent and $6.6 \%$ are least one of severe asthma. The percentages of the patients who were $58.4 \%$ treated with a single anti-asthmatic drug (monotherapy) excluding other concomitant medications used together. Conclusion: It has been concluded that a study may be more meaningful to further improve the prescribing as well as dispensing practices of the pharmacist through the successful implementation of interventional programs in health centers.

Keywords: Bronchial asthma, Children, Anti-asthmatics, Adverse drug reactions

Corresponding Author

Lalit Une, Professor and Head, Department of Paediatrics, JIIU's Indian Institute of Medical Science and Research, Jalna, Maharashtra, India. Email: lalit_68@yahoo.com
How to Cite this Article

Bansal S, Une L. A prospective study on the pharmacotherapy of bronchial asthma in pediatric patients at a tertiary care hospital; emphasis on adverse drug reactions. Pediatric Rev Int J Pediatr Res. 2020;7(2):104-113.

Available From

https://pediatrics.medresearch.in/index.php/ijpr/arti cle/view/579
To Browse

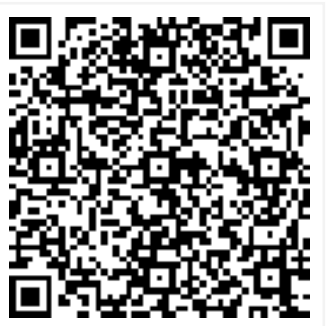

Manuscript Received 2020-01-20

Conflict of Interest No
Review Round 1 2020-01-30

Funding $\mathrm{Nil}$
Review Round 2 2020-02-07

Ethical Approval Yes
Review Round 3

Accepted 2020-02-13

Plagiarism X-checker $6 \%$

(C) 2020 by Sharad Bansal, Lalit Une and Published by Siddharth Health Research and Social Welfare Society. This is an Open Access article licensed under a Creative Commons Attribution 4.0 International License https://creativecommons.org/licenses/by/4.0/ unported [CC BY 4.0]. 


\section{Introduction}

Bronchial asthma is a chronic inflammatory condition of the respiratory tract associated with bronchial hyper-reactivity and airflow restriction due to airway smooth muscle contraction often leading to difficulty in breathing and hypoxia [1]. The pathogenesis of asthma involves mast cell activation, eosinophil, and T helper 2 ( $\mathrm{TH} \quad 2$ ) lymphocytes infiltration, IgE formation by $B$ lymphocytes, and release of other inflammatory mediators, chemokines, and growth factors by airway epithelium [2]. On allergen exposure, the asthmatic patients show an early phase characterized by sudden onset of bronchoconstriction, and then a late phase occurring 8-24 hours post-exposure. The late phase is characterized by the influx of inflammatory cells into the airways and airway hyper-responsiveness to nonspecific stimuli [3].

Asthma is a principal cause of illness in childhood and can lead to psychological disturbances in the family. Statistics say $10-15 \%$ of boys and $7-10 \%$ of girls may have asthma at some time during childhood. Before puberty boys are affected more than girl's incidence becomes equal thereafter [4]. Asthma affects an estimated 300 million individuals worldwide the prevalence of asthma is increasing especially in children's. The WHO has estimated that 15 million disability-adjusted life years are lost and 2, 50,000 asthma deaths are reported worldwide [5]. Approximately 5,00,000 annual hospitalization (34.6\% in individuals aged 18 years or younger) are due to asthma [6]. The cost of illness related to asthma is around $\$ 6.2$ billion. Each year; an estimated 1.81 million people $(47.8 \%$ individuals aged 18 years or younger) require treatment in the emergency department [7]. Proper drug therapy is one that controls both phases. Asthma produces a substantial economic and social burden on families and generally requires long-term treatment and patient cooperation to achieve clinical control [8]. According to Global Initiative for Asthma (GINA) guidelines, various drugs are suggested for the management of asthma that includes long and short-acting $\beta 2$ agonists (salbutamol, salmeterol, formoterol), corticosteroids (fluticasone, prednisolone, budesonide), xanthine derivatives (theophylline) and leukotriene receptor antagonists (Montelukast), mast cell stabilizers, antihistamines, and mucolytic. These drugs can be used alone or in conjunction with other antiasthmatic drugs [9].
Moreover, among children and adolescents aged 517 years asthma accounts for a loss of 10 million school days and cost caretaker $\$ 726.1$ million because of work absence [10]. There are only a few studies from India on the epidemiology of asthma. In a study conducted more than 30 years ago, the prevalence of asthma was reported to be $2.78 \%$ in an urban population aged 30-49 years [11]. Asthma is responsible for significant medical resource utilization and given that it is a chronic condition, cost-effectiveness is a major consideration in the evaluation of treatment options. With this point of view, the study has been designed. The objective of this study was to pool the data on drug utilization patterns and adverse drug effect analysis used for pediatric asthma patients. In addition, the antiasthmatic drug usage pattern, correlation between environmental factors and asthma and patient's knowledge of the drug used was also determined.

\section{Material and Methods}

Study Design: A prospective, observational, noninterventional study of children who presented between January 2018 and December 2019

Study center and patients consent: Department of Paediatric of Noor Hospital and parents provided written consent to enroll in the Paediatric Asthma study.

\section{Inclusion criteria}

- Pediatric patients of bronchial asthma (both acute and chronic cases)

- Patients of either gender within the age limit of 1-13 years

- Who attended the outpatient department (OPD) as well as the inpatient department (IPD),

- Willing to enroll in a study with informed consent forms were included in the study.

\section{Exclusion criteria}

- Patients who are $<1$ and $>13$ years,

- Patients with other co-morbid conditions like TB, Diabetes/renal failure

- Patients with other systemic disorders

- Patients who were immunocompromised were also excluded.

Sample size: The study included 100 patients who confirmed the following predetermined inclusion and exclusion criteria. 


\section{Method}

Once their consultation with the pediatrician was over, the prescriptions were collected and necessary details were noted on the questionnaire. The patient's parents were also interviewed on the predesigned questionnaire. The details of the drugs prescribed were noted down. After noting down the required parameters, prescriptions were returned to the patients. After the completion of the study, the questionnaires were analyzed to obtain the drug utilization pattern and from the Current Index of Medical Specialties (CIMS) and Indian Pharmaceutical Guide. It also included the OPD number, demographical details, and patients name, age, sex. A brief questionnaire was designed specifically for the study is attached to the case report form which chief complaints, and history of asthma, severity and the current status of asthma. The details of the drugs prescribed (dose, route, frequency, duration), the cost of therapy.

\section{Evaluation Parameters}

1) Prescription Indicators

01. A number of drugs/per prescription

02. Encounters with the brand name (\%)

Iii. Most commonly prescribed $\beta 2$ agonist

01. Most commonly prescribed Inhaled corticosteroid

\section{Encounter with antibiotics}

Parents of eligible patients were contacted by phone or in-person a pediatrician. Using a non-leading interview script, a standardized questionnaire was administered to identify any ADR-related drug cessation, reported spontaneously or after prompting, using three approaches. First, it was enquired about the occurrence and reason for any asthma drug cessation. Second, it was asked if the child had experienced an ADR to any asthma medication. Finally, a list of ADRs was read to parents to determine if any of them had ever occurred with any asthma drug. If an ADR was reported in any of these three questions, parents were asked to describe the type and onset of symptoms, circumstances related to the event, dose adjustments or drug discontinuation resulting from the ADR, and, when applicable, the evolution of the ADR after discontinuation of the drug (dechallenge) and after restarting the medication (rechallenge) [20].
ADR report to assess event severity, evolution and immutability using the Naranjo score [20], briefly, the Naranjo algorithm evaluates the drug causality for an adverse drug reaction based on 10 questions. Each answer is assigned a value $(-1$ to +2$)$ for a maximum score of 12 , with causality considered definite if the total score is $\geq 9$, probable if $5-8$, possible if $1-4$ and doubtful if $\leq 0$. Moreover, the severity of the reactions was analyzed using modified Hartwig and Siegel's scale.

Statistical analysis: Statistical Analysis was performed using Statistical Software SPSS 17.0. The Data was entered into the SPSS sheet and analyzed. The data was presented using frequencies, percentages along with appropriate graphs and charts. The quantitative variables were presented using descriptive statistics such as mean, and Standard deviation. The Association between variables was tested using the chi-square test. The level of significance was set at 0.05 . All $p$ values less than 0.05 are considered significant.

\section{Results}

During the study, 120 pediatric asthma patients' prescriptions were included for data analysis as per the inclusion and exclusion criteria. The study was conducted between January 2018 to December 2019 at Noor Hospital and IIMSR Medical college.

The various parameter analyzed are as follows

Table-1: Age-wise Distribution of Paediatric Patients

\begin{tabular}{|l|l|l|}
\hline Age (in a year) & No. of patients $(\mathrm{n}=\mathbf{1 2 0})$ & Percentage \\
\hline $1-4$ & 47 & 39 \\
\hline $5-8$ & 51 & 42 \\
\hline $9-13$ & 22 & 19 \\
\hline Total & 120 & 100 \\
\hline
\end{tabular}

The pediatric group patients were divided into three classes as per the age-group. Most of the pediatric patients suffering from asthma $42 \%$ were found in the age group of 5-8 years followed by (39\%) 1-4 years and the last one is $9-13$ years (19\%).

Table-2: Gender wise Distribution of Paediatric Patients

\begin{tabular}{|l|l|l|}
\hline \multicolumn{1}{|c|}{ Gender } & \multicolumn{1}{c|}{ No. of patients } & \multicolumn{1}{c|}{ Percentage } \\
\hline Male & 74 & 61.6 \\
\hline Female & 46 & 38.4 \\
\hline Total & 120 & 100 \\
\hline
\end{tabular}

Demographic analysis of data revealed that there were $61.6 \%$ male and $38.4 \%$ female in the study. 
Table-3: Grading of asthma severity (\% of patients).

\begin{tabular}{|l|l|l|}
\hline \multicolumn{1}{|c|}{ Grading } & \multicolumn{1}{c|}{ No. of patients } & \multicolumn{1}{c|}{ Percentage } \\
\hline Mild & 41 & 34.1 \\
\hline Moderate & 71 & 59.1 \\
\hline Severe & 8 & 6.6 \\
\hline Total & 120 & 100 \\
\hline
\end{tabular}

Out of 120 Paediatric asthma patients, 34.1\% were suffering from mild persistent and the remaining $59.1 \%$ were patients of moderate persistent and $6.6 \%$ are least one of severe asthma.

Table-4: Anti-asthmatic drug combinations

\begin{tabular}{|l|l|l|}
\hline \multicolumn{1}{|c|}{ Drug therapy } & \multicolumn{1}{c|}{ No. of patients } & Percentage \\
\hline Monotherapy & 70 & 58.4 \\
\hline Combination therapy & 50 & 41.6 \\
\hline Total & 120 & 100 \\
\hline
\end{tabular}

The percentages of the patients who received either monotherapy or combination therapy, i.e., two, three, or four-drug regimens, showed that $58.4 \%$, of all the patients, were treated with a single antiasthmatic drug (monotherapy) excluding other concomitant medications used together. $41.6 \%$ of children were treated with anti-asthmatic drug combinations. The results of this study showed that most of the patients received multiple drug therapy as compared to single-drug therapy. All the drugs were prescribed by their brand names.

\section{Table-5: Drugs used in asthma}

\begin{tabular}{|l|l|l|}
\hline \multicolumn{1}{|c|}{ Drug class } & No. of patients & Percentage \\
\hline Short acting $\beta 2$-agonists & 39 & 32.5 \\
\hline Long-acting $\beta 2$-agonists & 11 & 9.1 \\
\hline Steroids alone & 17 & 14.1 \\
\hline Leukotriene Modifiers & 3 & 2.5 \\
\hline Steroids + Beta-agonists & 39 & 32.5 \\
\hline Anticholinergic+ Beta-agonists & 11 & 9.1 \\
\hline
\end{tabular}

The overall utilization of Anti-asthmatic drugs among pediatric asthma patients was found to be short-acting $\beta 2$ Agonists (32.5\%) long-acting $\beta$ 2agonist (LABA) $(9.1 \%)$, steroids $(14.1 \%)$ and leukotriene modifiers $(2.5 \%)$. The pattern of drug prescription in asthmatics showed the highest prevalence of $\beta 2$ Agonists followed by corticosteroids and finally, the leukotriene modifiers. One additional antiasthmatic drugs: anticholinergics was also used among patients.

Table-6: Distribution According to Class of Drugs Prescribed (Asthmatic Medication)

\begin{tabular}{|c|l|c|}
\hline \multicolumn{1}{|c|}{ Norug } & No. patients & Percentage \\
\hline Salbutamol & 39 & 32.5 \\
\hline
\end{tabular}

\begin{tabular}{|l|l|l|}
\hline Salmeterol & 11 & 9.1 \\
\hline Deflazacort & 2 & 1.6 \\
\hline Budesonide & 9 & 7.5 \\
\hline Prednisolone & 6 & 5 \\
\hline Montelukast & 3 & 2.5 \\
\hline Salmeterol+Fluticasone & 39 & 32.5 \\
\hline Salbutamol+Ipratropium Bromide & 11 & 9.1 \\
\hline
\end{tabular}

Salbutamol is the most commonly used short-acting $\beta 2$ Agonists, Salmeterol was the most commonly used long-acting $\beta 2$ Agonists. Budesonide, Deflazacort, and Fluticasone are the most commonly used corticosteroids among children.

Table-7: Route of administration of Drugs

\begin{tabular}{|l|l|l|}
\hline \multicolumn{1}{|c|}{ Route } & \multicolumn{1}{c|}{ No. of patients } & \multicolumn{1}{c|}{ Percentage } \\
\hline Inhalational & 74 & 61.6 \\
\hline oral & 46 & 38.3 \\
\hline Total & 120 & 100 \\
\hline
\end{tabular}

Different dosage forms used by the asthmatic patient: $61.6 \%$ of patients were given by inhalational route and remaining were given by oral route $38.3 \%$.

Table-8: Gender of patients and adverse drug reaction $(n=120)$

\begin{tabular}{|l|l|l|l|}
\hline \multirow{2}{*}{ Gender } & \multicolumn{2}{|c|}{ No. of patients } & \multirow{2}{*}{ Total } \\
\cline { 2 - 3 } & With ADR (\%) & Without ADR $(\%)$ & \\
\hline Male & $8(6.6 \%)$ & $66(55 \%)$ & $74(61.6 \%)$ \\
\hline Female & $5(4.1 \%)$ & $41(34.1 \%)$ & $46(38.4 \%)$ \\
\hline Total & $13(10.8 \%)$ & $107(89.1 \%)$ & $120(100 \%)$ \\
\hline
\end{tabular}

During the study period, a total of 35 ADRs were reported among 330 patients. The incidence rate of ADRs was found to be $10.6 \%$. The current study revealed that out of 35 reported cases of ADR, 19 (54.28\%) occurred in males and $16(45.71 \%)$ in females as shown in Table 8.

Table-9: Percentage of various reported adverse drug reactions

\begin{tabular}{|l|l|l|}
\hline \multicolumn{1}{|c|}{ ADR } & No. of patients & Percentage \\
\hline Palpitation & 2 & 1.6 \\
\hline Dryness of mouth & 2 & 1.6 \\
\hline Headache & 3 & 2.5 \\
\hline Sore throat & 2 & 1.6 \\
\hline Oral candidiasis & 1 & 0.8 \\
\hline Nausea/vomiting & 1 & 0.8 \\
\hline Anorexia & 2 & 1.6 \\
\hline Total & 13 & 10.8 \\
\hline
\end{tabular}

The most commonly reported ADRs were $2.5 \%$ of headache, $1.6 \%$ of palpitation, dryness of mouth, sore throat, anorexia, and $0.8 \%$ of oral candidiasis nausea/vomiting. 
Table-10: Causality assessment of ADRs according to WHO-UMC scale

\begin{tabular}{|l|l|l|}
\hline \multicolumn{1}{|c|}{ Type of reaction } & \multicolumn{1}{c|}{ No. of patients } & \multicolumn{1}{c|}{ Percentage } \\
\hline Certain & 1 & 0.83 \\
\hline Probable & 5 & 4.1 \\
\hline Possible & 7 & 5.8 \\
\hline
\end{tabular}

On causality assessment by WHO-UMC method, it was observed that $1(0.83 \%)$ were certain, 5 (4.1\%) were probable and a maximum of 7 (5.8\%) was possible ADR.

Table-11: Severity of reported ADRs by modified by Hartwig and Siegel scale

\begin{tabular}{|l|l|l|}
\hline \multicolumn{1}{|c|}{ Type of reaction } & No. of patients & Percentage \\
\hline Mild & 8 & 6.6 \\
\hline Moderate & 5 & 4.2 \\
\hline Severe & 0 & 0 \\
\hline
\end{tabular}

Assessment of severity of recorded adverse drug reactions with the help of the Hartwig and Siegel scale showed that $8(6.6 \%)$ accounted for mild reactions and $5(4.2 \%)$ were moderate reactions. No severe ADR was recorded during the study period.

\section{Discussion}

The prescription-based study evaluates the rationality of the prescription. Guidelines for rational prescribing practices are put forth to improve the standards of prescribing [12]. An international body on asthma has enhanced the prescribing practice of the physicians through various recommendations. The present study was conducted in Noor hospital which caters to a population of Jalna. The demographic characteristics show the number of pediatric patients in the study. This is anticipated as Jalna is becoming a heavy industrial city and pollution producing units are gradually coming closer to the Hospital. These facts are further reinforced by a similar study in Taburet AM. [13] Whereas, demographic characteristics, of the present study found that more males (61.6\%) suffered from asthma than females (38.4\%).

In the present study, $58.4 \%$ of asthmatic patients were on single-drug therapy (monotherapy) and $41.6 \%$ Multiple drug therapy (combination). A similar study conducted at Dehradun, India, reported that $84 \%$ of asthmatic patients were on multiple drug therapy and only $16 \%$ of patients were on single-drug therapy [14]. The result of this study demonstrates that different prescribing patterns in comparison to published studies.
On the other hand, a study conducted by Pinal et al. showed that $84 \%$ of patients and $76 \%$ of patients in Shimpi et al. were given combination therapy over monotherapy $[15,16]$.

The overall utilization of Anti-asthmatic drugs among pediatric asthma patients was found to be $\beta 2$ Agonists (32.5\%), Corticosteroids (14.1\%) and leukotriene modifiers $(2.5 \%)$. Salmeterol among children was the most commonly used LABA, while Budesonide, Fluticasone were the more widely used Inhalational Corticosteroids. The results demonstrate that mast cell stabilizers are not used much clinically. They have been overshadowed by the other antiasthmatic medications. In the present study found that $61.6 \%$ of patients among children were prescribed with oral medicaments and $38.4 \%$ with inhalers. A similar study conducted by Shimpi et al. found that $54 \%, 34 \%$ and $12 \%$ of antiasthmatic drugs were prescribed orally, via inhalation and by injection respectively [16].

Prescription of inhalational dosage forms for antiasthmatic drugs was approximate similar in both the studies. The inhalation route causes a high local concentration in the lungs with a low systemic delivery, significantly improves the therapeutic effectiveness and minimizes systemic side effects. It was also found that $75 \%$ of the parents of pediatric patients were aware of the drug schedule. Satisfactory knowledge about spacer and meter dose inhalers was also found. However, most patients were unaware of the asthma control action plan. Thus, the present study highlights that certain steps towards patient education need to be taken in order to improve the awareness among the pediatrics patients regarding medication and management of asthma for a better prognosis. In the future, informative leaflets may be prepared and distributed among the patients based upon their awareness.

In the present study majority of the prescriptions used nebulization as a preferred route of drug delivery to manage acute exacerbations of asthmatic episodes. Nebulizer produces an aerosol by blowing air or oxygen through a solution to produce droplets requiring little coordination from the patient as a drug is inhaled through a facemask or a mouthpiece using normal tidal breathing. Thus, it is useful for patients who are unable to use conventional inhaler. The disadvantages of using a nebulizer include the long-time commitment maintenance treatments and lack of portability [17]. 
However, the inhalation therapy through metered dose inhalers was given to all patients who had treatment for acute exacerbation of bronchial asthma at the time of discharge. The inhalational route delivers more drugs locally and the dose used is also less with fewer side effects. This is in accordance with treatment guidelines, i.e. Inhalational therapy for asthma to be the first choice [18]. The effectiveness of inhaler therapy also depends on the inhaler technique.

Patients may not be adequately instructed in the inhaler technique, thereby reducing the amount of drug delivered to the lungs. Cochrane, in a study, stated it is important to reinforce the simple concept that failure to instruct patients on how to use inhalers and to reinforce these instructions will decrease compliance, whatever the drug or inhalation device [19].

The most commonly prescribed inhaled bronchodilator was salbutamol with ipratropium bromide $(32.5 \%)$ followed by formoterol with budesonide $(31.5 \%)$ which was in coherence with the study done in Malaysia in which salbutamol was the most commonly prescribed and also study done in Bareilly, which showed inhaled salbutamol was received by $100 \%$ of the patients irrespective of the severity $[20,21]$. The reason for using short-acting $\beta 2$ agonist i.e salbutamol is due to its rapid onset and its low cost. In the current study, injection hydrocortisone was also used in managing an acute asthma attack.

It prevents the side effect of inhaled medication which causes irritation on the respiratory tract. National Asthma Education and Prevention Program (NAEPP) guidelines recommend corticosteroids by oral route even for severe exacerbation and it is reported to be as effective as intravenous route [22].

Anticholinergics were not prescribed as monotherapy but were given in combination with, as they are preferred medication for treating asthma. Doxophylline is preferred over theophylline for it has less cardio-toxic effects than the former with preserved much-regulatory and anti-inflammatory properties. Hence, doxophylline may constitute a safe and effective alternative treatment to aminophylline/theophylline in the treatment of acute exacerbation of bronchial asthma [23].

However, Akram et al. conclude that there is no significant difference in spirometric variables between doxophylline and theophylline [24].
The conclusions of Akram et al. are further reinforced by the study of Margay et al [25], but he concludes that doxophylline has a better safety profile over theophylline.

Corticosteroids constituted the second most commonly used medication for the inhalational and oral route, and was prescribed in $14.1 \%$ of the prescriptions, in contrast, to study done by Sayadeda et al., corticosteroid was given by IV route in $100 \%$ cases of severe exacerbation and some cases of severe exacerbation were also given MgSO4 (28.57\%) for additional bronchodilation [26]. In addition to the reduction of severity and exacerbation, they reduce airway hyperresponsiveness.

They also help in reducing inflammation by inhibiting the activation and recruitment of $\mathrm{T}$ cells, macrophages, and dendritic cells, by decreasing mast cell survival, and by inhibiting the release of inflammatory mediators [27]. In addition, they reduce hospitalization, improve quality of life, and reduce overall mortality and morbidity. A recent systematic review established the myriad benefits of systemic steroids in the management of asthma [28]. Montelukast, a leukotriene receptor antagonist $(2.5 \%)$ was seen in the prescription. According to Rajathilagam et al. it was prescribed as a fixed-dose combination with levocetirizine (36.8\%) [29].

In the present study, it was observed that in a period of 2 years, a total of 13 ADRs occurred affecting patients of either gender but the number was higher in males as compared to females. This does not comply with the statement that females are more sensitive to the effect of drugs as in comparison to males [30].

During the course of pharmacotherapy administered to the patient, short-acting $\beta 2$ agonist (salbutamol), as well as leukotriene receptor antagonist (montelukast), were found to be responsible for causing the highest number of ADRs i.e. 10 $(28.57 \%)$. It also stated that followed by corticosteroids (budesonide) causing $17.14 \%$ and anticholinergics (ipratropium bromide) causing $14.28 \%$ of ADRs [31].

Furthermore, in the current study, it was observed that the administration of salbutamol by inhalational route in children resulted in palpitations, nausea/vomiting and rhinorrhoea out of which palpitations were the most frequently accounted ADRs. 
The dose was decreased in one case of palpitations whereas in the case of rhinitis, metered-dose inhaler (MDI) salbutamol was discontinued and a combination of salbutamol and ipratropium, bromide was administered via nebulization.

With the use of montelukast, pediatric patients reported headaches as the most common ADR for which symptomatic treatment was given. These findings are consistent with a review article by Gupta et al (2016), which stated that headaches were most frequently reported to the Dutch database for both the whole population and children [32]. Other ADRs encountered due to administration of montelukast include cough, nausea/vomiting, upper respiratory tract infections, rhinorrhoea, and anorexia. In addition, it was also observed that the administration of inhalational budesonide in children majorly resulted in sore throat and oral candidiasis. Antifungal therapy was given to manage oral candidiasis whereas, for sore throat, patients and their parents were counseled to ensure oral hygiene after every inhalation.

Similarly, the most common ADR encountered with the use of ipratropium bromide was dryness of the mouth $(11.42 \%)$. Out of these 13 cases, 8 were mild reactions whereas 5 was of moderate and was managed by discontinuation of ipratropium bromide. However, the milder reaction was only symptomatically managed by rehydration. All drugrelated ADRs were evaluated for causality in accordance with Naranjo's scale as well as the WHO-UMC scale. Whereas, type of reaction such as 0.83 was certainly followed by $4.1 \%$ were found to be probable ADRs and $5.8 \%$ as the possible ADRs. None of the reported ADRs were found to be fatal, life-threatening or needed hospital admission for management.

\section{Limitation of the study}

- As for all observational studies, there are few limitations worth to be mentioned. First, as the inclusion of the clinical data (e.g. lung function parameter) was not done and thus focus on drug prescription was more instead of analyzing patients in detail comparing on- and off-label users (as already done.

- Second, there are some uncertainties in matching specific ICD-codes needed for analyzing databases and indications stated in the (summary of product characteristics) SPC in particular when general terms have been used in the SPC.
This might have influenced the number of calculated off-label prescriptions. Nevertheless, most of the terms used for defining off-label usage are comparable to other publications [1].

- Third, the current study was lack of follow up and cost-effectiveness which should have been done. For higher authenticity, more number of prescriptions should have been included in the current study.

- Lastly, only a few serious ADRs were reported, but patients' withdrawal from clinical studies due to ADRs should be investigated more clearly.

\section{Conclusion}

Asthma symptoms aggravated during the daytime and winter season. $\beta 2$ agonists and Combinations with corticosteroids are the most commonly prescribed combination drugs for asthma followed by corticosteroids alone. Nebulization was the preferred route to tackle the acute exacerbation of asthmatic symptoms. In addition, adverse drug reactions associated with anti-asthmatic drugs are quite common. This study highlights the incidence and pattern of ADRs associated with pharmacotherapy of pediatric bronchial asthma. As such, increased awareness regarding the occurrence of the adverse drug reactions among parents and the Health care professional may result in early detection of ADRs, their early reporting and minimize the risk of ADR related harms. Physicians seem to be aware of recent guidelines in the management of asthma. This may be partially attributed to mandatory CMEs, protocol-based treatment, and impact of extensive asthma education campaign. Further studies may help to improve the prescribing and dispensing practices of pharmacists through the successful implementation of interventional programs in health care centers.

\section{What does the study add to the existing knowledge?}

The current study found that pediatrics patients especially males age between 5-8 showed a greater incidence of asthma but were unaware of antiasthmatic drugs. It was also noticed that pharmacists usually distributed medicines without giving any written or detailed oral instructions. Thus, the current study highlights the lacunae in the prescription trends which prevent proper, rational utilization of drugs by patients. 
This study also highlights some very important issues about the information on ADRs of asthma medication in clinical studies. Firstly, the patients included are mostly male at the age of 5-8 years. Information on ADRs in younger children, who are more vulnerable, is scarce.

Although in practice salbutamol and steroids are used most frequently, most information on ADRs was on leukotriene receptor antagonists. It was believed that giving correct and reliable information on ADRs in asthma medication in clinical studies is the responsibility of researchers, authors, editors of journals, pharmaceutical companies, and regulatory agencies.

\section{Author's Contributions}

Dr. Sharad Bansal: Concept and Manuscript preparation, Dr. Lalit Une: Study design and data analysis.

\section{Reference}

01. Shaji J, Lodha S. Management of Asthma- A Review. Indian J Hosp Pharmacy. 2008;45;88-100. [Crossref][PubMed][Google Scholar]

02. American Academy of Pediatrics Subcommittee on Diagnosis and Management of Bronchiolitis. Diagnosis and management of bronchiolitis. Pediatr. 2006;118(4)1774-1793. doi: 10.1542/peds.20062223 [Crossref][PubMed][Google Scholar]

03. Papi A, Canonica GW, Maestrelli P, Paggiaro P, Olivieri D, Pozzi E, et al. Rescue use of beclomethasone and albuterol in a single inhaler for mild asthma. N Engl J Med. 2007;356(20)20402052. doi: 10.1056/nejmoa063861 [Crossref] [PubMed][Google Scholar]

04. Mishra N, Rao KVR, Padhi Sk. Asthma education for better compliance in disease management. Indian J Allergy Asthma Immunol. 2005;19;25-28. [Crossref][PubMed][Google Scholar]

05. Golshan M, Amra B, Zadeh ZM. Prevalence of asthma in high school adolescents of Isfahan. Med J Iran Hosp. 2001;4;35-40. [Crossref][PubMed] [Google Scholar]

06. Taylor DR, Bateman ED, Boulet LP, Boushey HA, Busse WW, Casale TB, et al. A new perspective on concepts of asthma severity and control. Eur Respir J. 2008;32(3)545-554. doi: 10.1183/09031936. 00155307 [Crossref][PubMed][Google Scholar]
07. Anil K, Tiwari HK, Kulkarni SK. Drug utilization Assessment in Asthma Therapy through prescription Monitoring. Indian J Hosp Pharmacy. 2004;2;70-72. [Crossref][PubMed][Google Scholar]

08. Ip M, Lam K, Yam L, Kung A, Ng M. Decreased bone mineral density in premenopausal asthma patients receiving long-term inhaled steroids. Chest. 1994;105(6)1722-1727. Doi: 10.1378/chest.105.6. 1722 [Crossref][PubMed][Google Scholar]

09. Global Initiative for Asthma. Global strategy for asthma management and prevention- NHLBI/WHO workshop report. Bethesda, MD- National heart, lung, and blood institute, 2006. Aust Prescrib. 2001;24;29-31. Available at [Article][Crossref] [PubMed][Google Scholar]

10. Ungar WJ, Coyte PC. Prospective study of the patient level cost of asthma care in children. Pediatr Pulmonol. 2001;32(2)101-108. [Crossref][PubMed] [Google Scholar]

11. Johnson CE. Aerosol corticosteroids for the treatment of asthma. Drug Intell Clin Pharm. 1987;21(10)784-790. doi: 10.1177/106002808702101002 [Crossref][PubMed] [Google Scholar]

12. Taburet AM Schmit B. Pharmacokinetic optimi zation of asthma treatment. Clin Pharmacokinet. 1994;26(5)396-418. doi: 10.2165/0003088-19942 6050-00006 [Crossref][PubMed][Google Scholar]

13. Arumugam V, Preeti K, Vijay J, Awanish $P$, Poonam T. Drug Utilization Assessment in Asthma Therapy through Prescription Monitoring at Dehradun Hospitals. Indian J Allergy Asthma Immunol. 2008;22(1)15-18. [Crossref][PubMed] [Google Scholar]

14. Patel PD, Patel RK, Patel NJ. Analysis of Prescription Pattern and Drug Utilization in Asthma Therapy. Int Res J Pharm. 2012;257-260. [Crossref] [PubMed][Google Scholar]

15. RD Shimpi, PS Salunkhe, SR Bavaskar, GP Laddha, A Kalam A Khalik Patel. Drug utilization evaluation and prescription monitoring in asthmatic patients. Int J Pharm Biol Sci. 2012;2(1)117-122. [Crossref][PubMed][Google Scholar]

16. Sen EF, Verhamme KM, Neubert A, Hsia $Y$, Murray $M$, Felisi $M$, et al. Assessment of pediatric asthma drug use in three European countries- a TEDDY study. Europe J Pediatr. 2011;170(1)81-92. doi: 10.1007/s00431-010-1275-7 [Crossref] [PubMed][Gooqle Scholar] 
17. Elkout H, Helms PJ, Simpson CR, McLay JS. Changes in primary care prescribing patterns for paediatric asthma- a prescribing database analysis. Arch Dis Childhood. 2012;97(6)521-525. doi: 10.1136/adc.2010.206268 [Crossref][PubMed] [Google Scholar]

18. Greenstone II, Chroinin MN, Lasserson TJ, Ducharme F. Combination of inhaled long-acting beta2-agonists and inhaled steroids versus higher dose of inhaled steroids in children and adults with persistent asthma. Cochrane database of systematic reviews. 2005(4)CD005533. doi: 10.1002/14651858.cd005533 [Crossref][PubMed] [Google Scholar]

19. Ducharme FM, Chroinin MN, Greenstone I, Lasserson TJ. Addition of long-acting beta2-agonists to inhaled steroids versus higher dose inhaled steroids in adults and children with persistent asthma. Cochrane Database of Systematic Reviews. 2010(4)CD005533. doi: 10.1002/14651858.cd005533.pub2 [Crossref] [PubMed][Google Scholar]

20. Thamby SA, Juling $P$, Xin BTW, NC Jing, Retrospective studies on drug utilization patterns of asthmatics in a Government hospital in Kedah, Malaysia. Int Curr Pharm J. 2012;1(11)353-360. doi: 10. 3329/icpj.v1i11.12060 [Crossref][PubMed] [Google Scholar]

21. Rao C, Ramakrishnan KG, Somashekar A R. Patterns of health care for children with asthma- A qualitative study. J Pediatr Res. 2017;4(7)446-452. doi: 10.17511/ijpr.2017.07.03 [Crossref][PubMed] [Google Scholar]

22. NAEPP Expert Panel Report- guidelines for the diagnosis and management of asthma-updates on selected topics 2002. Bethesda, MD- National heart, lung, and blood institute, 2002. (NIH Publication No 02-5075). Available at [Article][Crossref][PubMed] [Google Scholar]

23. Barben J, Kuehni CE, Trachsel D, Hammer J. Swiss Paediatric Respiratory Research G. Management of acute bronchiolitis- can evidence based guidelines alter clinical practice?. Thorax. 2008;63(12)1103-1109. doi: 10.1136/thx.2007.094706 [Crossref][PubMed] [Google Scholar]
24. MF Akram, M Nasiruddin, Z Ahmad RA Khan. Doxofylline and theophylline- a comparative clinical study. J Clin Diagn Res. 2012;6(10)1681-1684. doi: 10.7860\%2FJCDR\%2F2012\%2F4697.2643

[Crossref][PubMed][Google Scholar]

25. SM Margay, S Farhat, S Kaur, HA Teli. To study the efficacy and safety of doxophylline and theophylline in bronchial asthma. J Clin Diagn Res. 2015;9(4)5-8. doi: 10.7860/jcdr/2015/12438.5743 [Crossref][PubMed][Google Scholar]

26. K Sayadeda, NA Ansari, QS Ahmed, P Upadhyay, $S$ Dey, A Madhwar. Drug utilization study of antiasthmatic drugs in paediatric age group in a tertiary care teaching hospital, Bareilly, UP - India. Int J Univ Pharm Biosci. 2013;2(3)145-156. [Crossref][PubMed][Google Scholar]

27. Arellano FM, Arana A, Wentworth CE, Vidaurre CF, Chipps BE. Prescription patterns for asthma medications in children and adolescents with health care insurance in the United States. Pediatr Allergy Immunol. 2011;22(5)469-476. doi: 10.1111/j.1399-3038.2010.01121.x [Crossref] [PubMed][Google Scholar]

28. T Rajathilagam, T Sandozi, AD Nageshwari, P Paramesh, $\mathrm{R}$ Jamunarani. Drug utilization study in bronchial asthma in a tertiary care hospital. Int J Pharm. 2012;3(2)297-305. [Crossref][PubMed] [Google Scholar]

29. Bygdell M, Brunlöf G, Wallerstedt SM, Kindblom JM. Psychiatric adverse drug reactions reported during a 10-year period in the Swedish pediatric population. Pharmacoepidemiol Drug Saf. 2012;21(1)79-86. doi: 10.1002/pds.2265 [Crossref] [PubMed][Google Scholar]

30. Naranjo CA, Busto U, Sellers EM, Sandor P, Ruiz I, Roberts EA, et al. A method for estimating the probability of adverse drug reactions. Clinical Pharmacology \& Therapeutics. 1981;30(2)239-245. doi: 10.1038/clpt.1981.154 [Crossref][PubMed] [Google Scholar]

31. Gupta R, Fonacier LS. Adverse effects of nonsystemic steroids (inhaled, intranasal, and cutaneous)- a review of the literature and suggested monitoring tool. Curr Allergy Asthma Rep. 2016;16(6)44. doi: 10.1007/s11882-016-0620-y [Crossref][PubMed][Google Scholar] 